\section{Toward better counseling for Down syndrome}

To the Editor: I read the three commentaries regarding the counseling for parents with a child with Down syndrome published in the August 2011 issue of the journal. ${ }^{1-3} \mathrm{I}$ am writing to elaborate on some of the ideas expressed in them to address the issue of dissatisfied parents and to suggest improvements in the overall health care of people with Down syndrome.

In my view, pre- and postnatal situations need slightly different strategies. In the prenatal setting, in addition to being nondirective, noncoercive, and unbiased, it is important to present the full spectrum of medical conditions prone to occur with Down syndrome. To most parents, the terms "mild" and "moderate" mental retardation do not mean much, much less the intelligence quotients. Rather, they are interested in the quality of life a child with Down syndrome will have. To that end, parents should be given the range of observed outcomes: can children with Down syndrome live independently as adults, can they earn a living to some extent, and what is the availability of existing social and educational services? Examples of lifestyles of cases with best outcomes as well as those of intermediate and low achievers would further their understanding. Parents need to know that many adults with Down syndrome can expect to function well enough to live in a group home and hold a meaningful job because of improvements in health care and better education, and more are being raised at home. As suggested by Van Riper and Choi, ${ }^{3}$ some discussion regarding the variability in adaptation of parents to raising a special-needs child needs to occur. Some parents feel their life enriched by such a child and some feel the burden too difficult to cope with. Ideally, the prenatal genetic counseling staff should get the pediatric genetic counselors/MDs involved because they have firsthand ongoing experience of guiding the health-care supervision of children with Down syndrome. This joint effort brings more authenticity to the counseling session even though the prenatal staff may be well trained and well versed in all the aspects of Down syndrome.

Counseling for parents in the newborn period is well covered in the commentaries by the McCabe and $\mathrm{McCabe}^{1}$ and Van Riper and Choi. ${ }^{3}$ To reiterate, it is important to congratulate the parents for having a new baby and assure them that the doctor/ genetic counselor are there to support them. The overall tone of the discussion should convey a message to the parents that they and the pediatrician/geneticist will work together as a team to maximize the child's health and intellectual and emotional development. Many published guidelines ${ }^{4-7}$ list age-specific issues to be covered; thus, the counseling is broken up over many sessions covering the entire life of a person. Usually parents are unprepared to hear and digest all the information in the newborn period. As they get to know their baby, they have follow-up questions and are eager to learn what to expect and how to be proactive for that stage of the child's life. The education of residents in genetics needs to be modified as well. Typically, physicians in genetic residency see a prospective couple for prenatal counseling and a newborn baby for diagnosis and genetic counseling. They are less likely to see older children and adults with Down syndrome for a follow up. Therefore, they lack experience in dealing with problems that appear later in the life, including sleep apnea, loss of hearing, and hypothyroidism. Psychosocial and family concerns such as vocational training, applying for Supplemental Security Income, and sexuality may not be addressed. This needs to be changed such that physicians in genetic residency have firsthand experience in implementing the published guidelines for people with Down syndrome of a variety of ages.

Although the pediatrician is the ideal physician to address most of the parents' questions and advocate for the child with Down syndrome, my experience for the past 30 years is that only a few pediatricians are actually able to provide such counseling for a variety of reasons. Therefore, periodic visits with the geneticists are important. If counseling as part of primary care by a pediatrician is better reimbursed, perhaps the situation will improve.

\section{DISCLOSURE}

The author declares no conflict of interest.

\section{Erawati V. Bawle, MD, FACMG ${ }^{1}$}

${ }^{1}$ Department of Pediatrics, Wayne State University, Children's Hospital of Michigan, Detroit, Michigan, USA. E-mail: ebawle@wayne.edu

\section{REFERENCES}

1. McCabe LL, McCabe ERB. Down syndrome: coercion and eugenics. Genet Med 2011;13:708-710.

2. Flessel MC, Lorey FW. The California Prenatal Screening Program: "options and choices" not "coercion and eugenics". Genet Med 2011;13:711-713.

3. Van Riper M, Choi H. Family-provider interactions surrounding the diagnosis of Down syndrome. Genet Med 2011;13:714-716.

4. Bull MJ. Committee on Genetics. Health supervision for children with Down syndrome. Pediatrics 2011;128:393-406.

5. Bawle EV. Down syndrome: managing the child and the family. In: Mclnerny TK, Adam HM, Campbell DE, Kamat DM, Kelleher KJ (eds). American Academy of Pediatrics Textbook of Pediatric Care. American Academy of Pediatrics: Elk Grove Village, IL, 2009:2016-2026.

6. Lou IT, McCoy EE. Down Syndrome: Advances in Medical Care. Wiley-Liss: New York, 1992.

7. Pueschel SM. A Parent's Guide to Down Syndrome: Toward a Brighter Future. Brookes Publishing: Baltimore, MD, 1990.

doi:10.1038/gim.2011.14 